\title{
Numerical simulation of the temperature field of cold metal transfer welding pool
}

\author{
Kaiyuan Wu*, Zuwei He**, Zhongli Dong***, Yanlin Lan**** \\ *South China University of Technology, Guangzhou 510640, China, E-mail: wuky@scut.edu.cn \\ **South China University of Technology, Guangzhou 510640, China, E-mail: hezw@163.com \\ ***Electric Power Research Institute of Guangdong Power Grid Corporation, Guangzhou, 510080, China, \\ E-mail:dongzhongli@sohu.com \\ ****South China University of Technology, Guangzhou 510640, China, E-mail: lanyl@163.com \\ cross $^{\text {ref }}$ http://dx.doi.org/10.5755/j01.mech.22.4.16163
}

\section{Introduction}

Cold Metal Transfer (CMT) technology is a brandnew revolutionary short-circuit transfer technology, which realizes metal transfer at a current of nearly zero. At a state of short-circuit, the welding wire cannot proceed but sets back to extinguish the arc due to the very short course of thermal input by the arc, so that the thermal input decreases rapidly and becomes smaller due to the lower temperature of arc and metal than those through the traditional MIG welding [1-4]. The welding pool is the most important and the most complicated position during the welding, which involves the combined action of electric, thermal, magnetics and fluid. At present, due to the limitation of experimental conditions, for example, the extreme high luminance of the arc that might "mask" the behavior of the weld pool, it is very difficult to observe the welding pool through the experimental means, and the welding pool has been quantitatively studied through the numerical simulation technology by more and more welding researchers [5, 6]. ANSYS (a finite element analytical software) is the sole software to enable the multiple fields and the multi-field coupling analysis and thus enjoys a leading position in the finite element analytical software [7]. Specific to the CMT welding technology, this article conducts a research in the numerical simulation of the temperature field of CMT welding pool by means of the ANSYS, a finite element analytical software.

\section{Modeling of numerical simulation of the temperature field of CMT welding pool}

\subsection{Establishment of thermal source model of CMT welding}

The establishment of thermal source model of welding is the prerequisite for analyzing the welding thermal course and pool behavior. Dependent on the action mode, the welding thermal source is treated as centralized, plane-distributed and volume distributed one respectively. During the CMT welding, a greater depth/width ratio of welding seam is produced for a very great influence of thermal flow along the direction of workpiece thickness, and thus the thermal source should be treated as a certain proper volume distributed one. In order to take into account the distribution of arc thermal flow along the direction of workpiece thickness, the volume distributed thermal source can be described as the ellipsoid mode (including the semi-ellip- soid and dual-ellipsoid). During the CMT welding, the influence of welding speed rate in the heating area in the front arc is smaller than that at the back arc, making the heating area a double semi-ellipsoid instead of a single semi-ellipsoid symmetrical at the central line of arc, with the two semi-ellipsoid shape different from each other. Therefore, the volume distributed thermal source acted on the workpiece is divided into front and rear part. Assuming for the semi-axis of double semi-ellipsoid, the thermal flow distribution in the front and rear semi-ellipsoid can be expressed as [8]:

$$
\left.\begin{array}{l}
q_{f}(x, y, z)=\frac{6 \sqrt{3}\left(f_{f} Q\right)}{a_{f} b_{h} c_{h} \pi \sqrt{\pi}} \exp \left(-\frac{3 x^{2}}{a_{f}^{2}}-\frac{3 y^{2}}{b_{h}^{2}}-\frac{3 z^{2}}{c_{h}^{2}}\right), \\
x \geq 0 \\
q_{r}(x, y, z)=\frac{6 \sqrt{3}\left(f_{r} Q\right)}{a_{r} b_{h} c_{h} \pi \sqrt{\pi}} \exp \left(-\frac{3 x^{2}}{a_{r}^{2}}-\frac{3 y^{2}}{b_{h}^{2}}-\frac{3 z^{2}}{c_{h}^{2}}\right), \\
x<0
\end{array}\right\},
$$

where $a_{f}, a_{r}, b_{h}, c_{h}$ are the form parameters of thermal source; $Q$ - heat input, $\mathrm{W}, Q=U I ; \eta$-heat efficiency; $U$ - welding voltage, $\mathrm{V} ; I$ - welding current, A; $f_{f}, f_{r}$ are the distribution parameter of front and rear energy, $f_{f}+f_{r}=2$

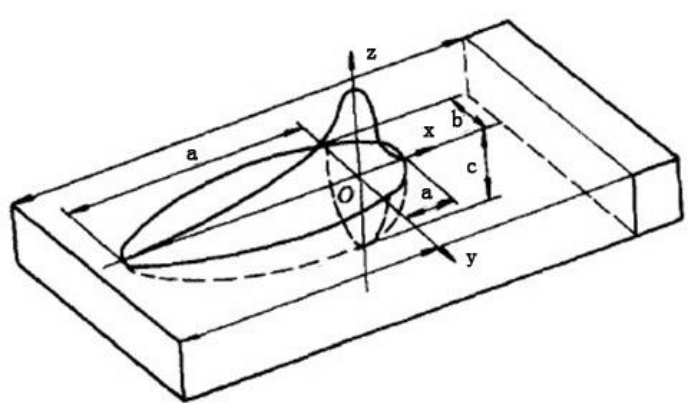

Fig. 1 Thermal source of dual-ellipsoid

As shown in Fig. 1, the thermal source is regarded as rotational semi-ellipsoid symmetrical at Z-axis, and the thermal flow distribution can be uniformly expressed as:

$q_{f}(x, y, z)=q(0,0,0) \exp \left(-\frac{3 x^{2}}{a^{2}}--\frac{3 y^{2}}{b^{2}}--\frac{3 z^{2}}{c^{2}}\right)$ 
where $a=a_{f}=a_{r}, b=b_{h}, c=c_{h}$. And $q(0,0,0)$ is the maximum density of thermal flow at the center of thermal source, which can be expressed as:

$$
q(0,0,0)=\frac{6 \sqrt{3} Q}{a^{2} b \pi \sqrt{\pi}},
$$

where parameters like $a, b, c$ and so on are dependent on front edge, rear edge, width and depth of pool. Note that the width and depth of pool can be measured on the cross section macroscopic metallographic view of the pool. $Q$ represents the arithmetic mean value of energy transferred to the arc each cycle that contains vigorous switch of voltage and current between the peak and base pulse as required by the characteristic of CMT welding. $Q$ can be determined by continuously sample the voltage and current within one cycle and calculate the arithmetic mean value. Welding thermal efficiency $\eta=75 \%$. The wire retraction assists metal detachment during the short circuit, thus the metal can transfer into the welding pool without the aid of the electromagnetic force. The thermal enthalpy brought by metal into pool is not ignorable, and thus has been taken into account when calculating the welding thermal efficiency.

\subsection{Treatment of reinforcement in the CMT welding seam model}

During the CMT welding, under the action of arc pressure, metal impact and surface tension, the surface of pool becomes concave-convex: in the front of pool, due to the continuous impact of metal and the action of arc force, the surface of pool becomes obviously concave; and at the back of pool, with the increase of filling metal and the concave deformation of front pool, the rear pool becomes convex to produce a reinforcement. Therefore, the weld reinforcement of welding seam should be considered: such reinforcement is added onto the workpiece before calculation, and treated by the unit activation method during the calculation. The result of the subsequent simulation will be directly influenced by the way to preset the shape of weld reinforcement for grid division before calculation.

As shown in Fig. 2, the contour curve for the cross section of reinforcement of welding seam is assumed as follows $[9,10]$ :

$$
y=a x^{2}(a<0) .
$$

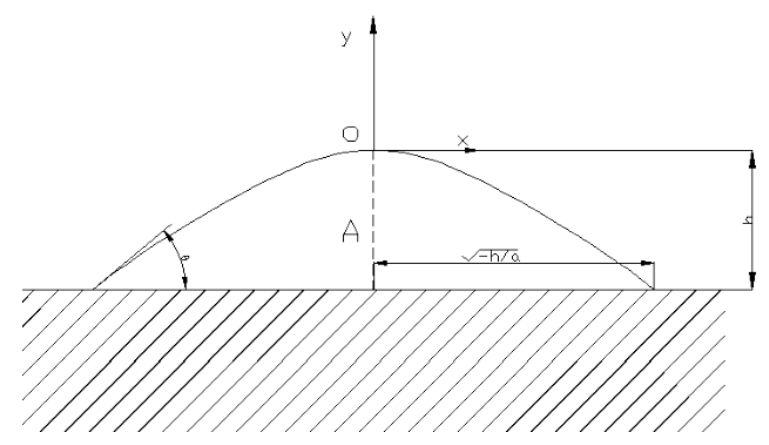

Fig. 2 Cross section of reinforcement of welding seam

As properly selected according to the actual conditions of welding process, the following equation is obtained via Fig. 2:

$$
\left.\frac{d y}{d x}\right|_{y=-h}=\tan \theta
$$

i.e.

$$
\left.\frac{d y}{d x}\right|_{y=-h}=\left.2 a x\right|_{x=-\sqrt{\frac{h}{a}}}=-2 a \sqrt{-\frac{h}{a}}=\tan \theta .
$$

So,

$$
h=-\frac{\tan ^{2} \theta}{4 a} .
$$

Due to the known amount of fused-on metal within a unit time (i.e. the cross section of metal liquid in the diagram, $A$, is known), the following equation is obtained:

$$
A=\frac{\pi d_{f}^{2} v_{f}}{4 v_{0}}
$$

where $a_{f}$ is the diameter of welding wire, $v_{f}$ is the speed of wire feeding and $v_{0}$ is the speed of welding.

From equation:

$$
A=2 \int_{0}^{\sqrt{-\frac{h}{a}}}\left(a x^{2}+h\right) d x .
$$

Eq. (11) is deduced:

$$
a^{2}=\frac{2 v_{0} \tan ^{3} \theta}{3 \pi d_{f}^{2} v_{f}} \text {. }
$$

In Eq. (11), the $a$ value is first obtained, and then the $h$ value is obtained.

\subsection{Grid division for calculating the temperature field of CMT welding}

Since the steel plate is symmetrical, only the half of welding seam is analyzed. In order to assure the calculation accuracy and save the calculation resource, the unit is divided to the non-uniform grid. While modeling, at the position of workpiece with a greater temperature gradient (especially near to the thermal source), the grid is divided in a finer way so as to obtain a higher unit density; and at the position far away from the thermal source, due to smaller temperature gradient, the grid is divided in a coarser way so as to balance the speed and accuracy of calculation.

In this article, the grid is divided in a finer way at the area of welding seam, in a coaser way at the area far away from the welding seam, and in a free way at the area of transfer respectively. The conflict between the accuracy and time of calculation is solved through the non-uniform grid of 8-node hexahedron. The workpiece is divided into three parts: the area of welding seam, the area of transfer, and the area far away from welding seam. The grid is divided in a denser way (grid size $0.0002 \mathrm{~m}$ ) at the area of welding seam, in a coarser way (grid size $0.005 \mathrm{~m}$ ) at the area far away from the welding seam, and in a free way at the transition zone respectively. The finite element model is 
established in Fig. 3.

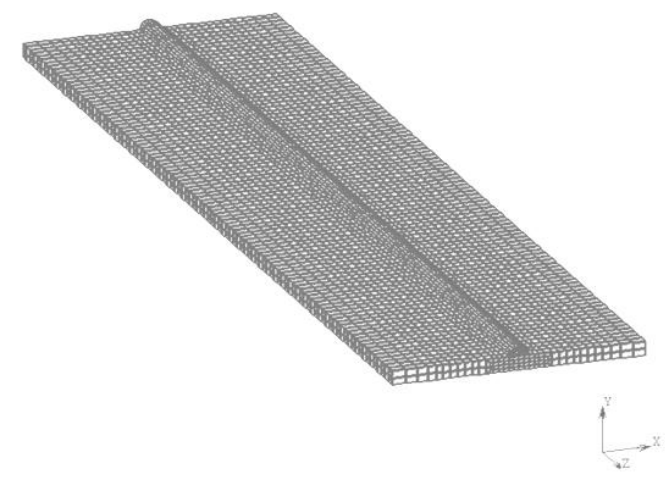

Fig. 3 Finite element model

\section{Numerical simulation the temperature field of CMT welding pool}

For the $16 \mathrm{Mn}$ steel plate, a common material in a power plant, the numerical simulation of surface welding is conducted with the following process parameters: welding voltage at $15.2 \mathrm{~V}$, welding current of $155 \mathrm{~A}$, welding wire ER70S-6, wire feeding speed at $9.0 \mathrm{~m} / \mathrm{min}$, welding speed at $11.0 \mathrm{~mm} / \mathrm{s}$, and welding mode of surfacing welding. The $16 \mathrm{Mn}$ steel plate used in the numerical simulation aforementioned features a dimension of $120 \mathrm{~mm} \times 60 \mathrm{~mm} \times 6 \mathrm{~mm}$ with the following thermo-physical properties.

\subsection{Distribution characteristic of the temperature field of CMT welding}

According to the established 3D numerical simulation model of transient thermal transfer, the numerical simulation is conducted in the field of the temperature of pool with the parameters mentioned above. Fig. 4 shows the distribution diagram of transient temperature field at the center of welding seam at different time (i.e. $t=2 \mathrm{~s}, 4 \mathrm{~s}, 6 \mathrm{~s}, 8 \mathrm{~s}$ and $10 \mathrm{~s}$ ), as the thermal source moves along the direction of plate length. Influenced by the movement direction of thermal source, the metal behind the thermal source has a temperature distribution of semi-ellipsoid with a larger heating area, and that before the thermal source has a smaller heating area.

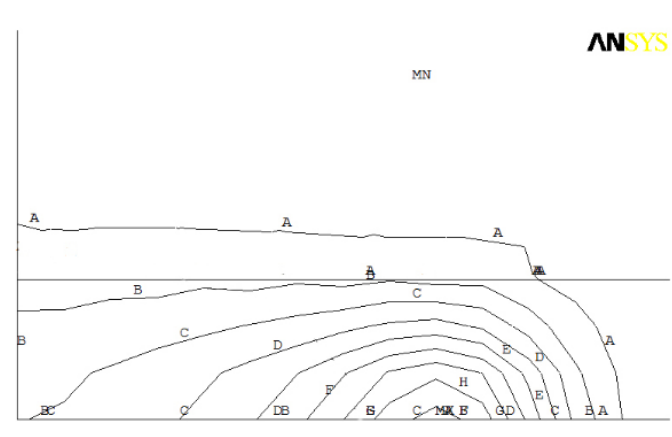

a

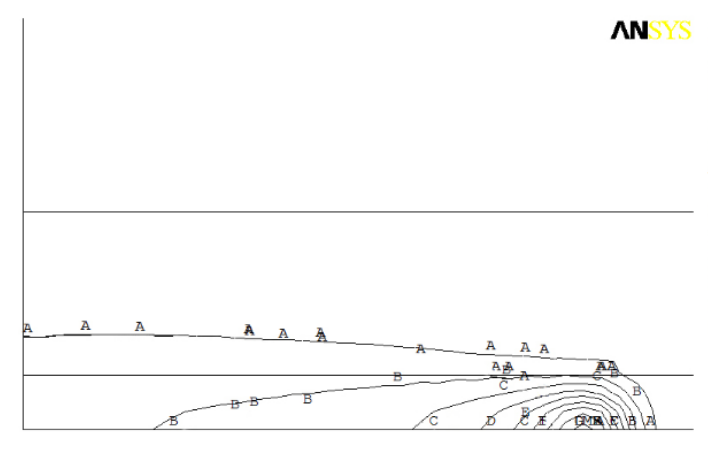

$\mathrm{c}$
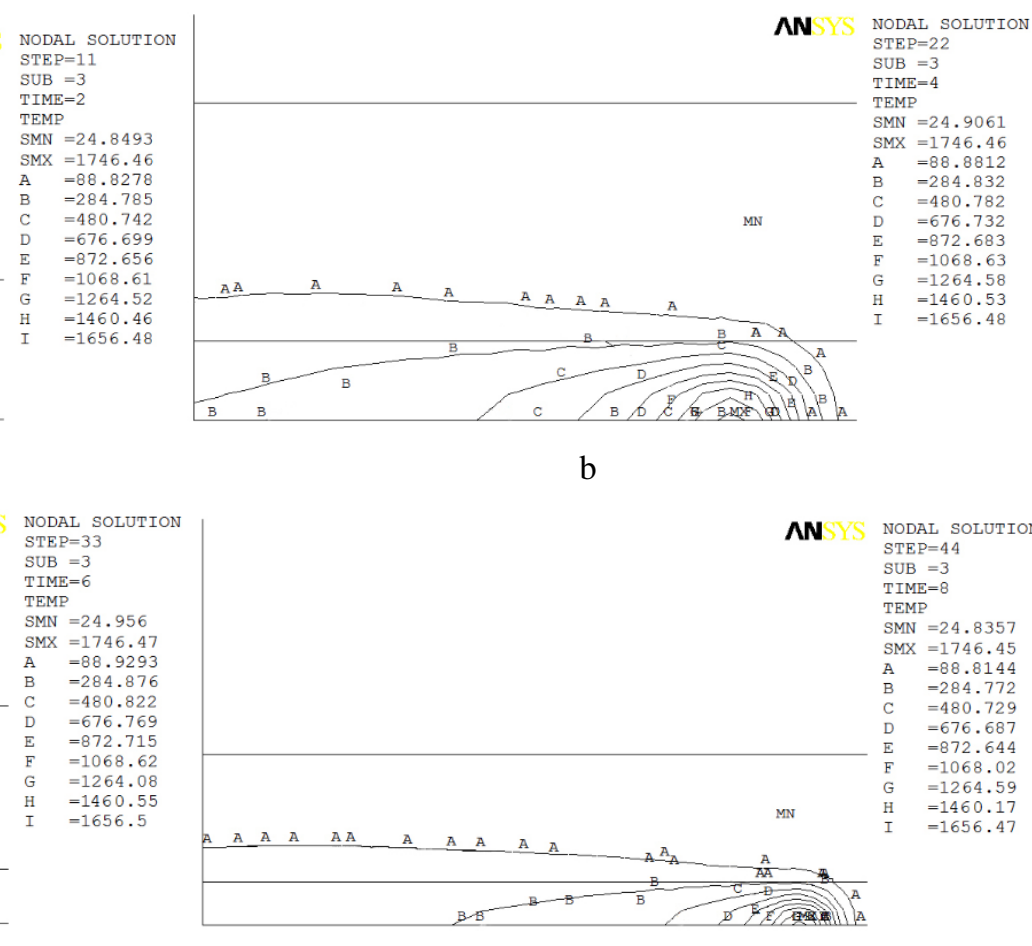

$\mathrm{b}$

\section{(1)}

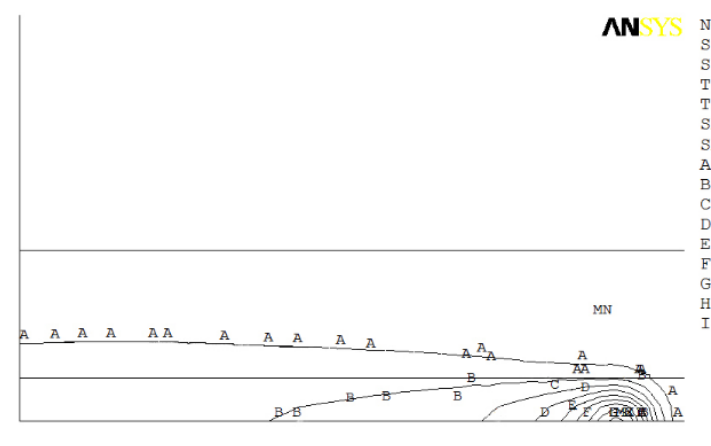

d

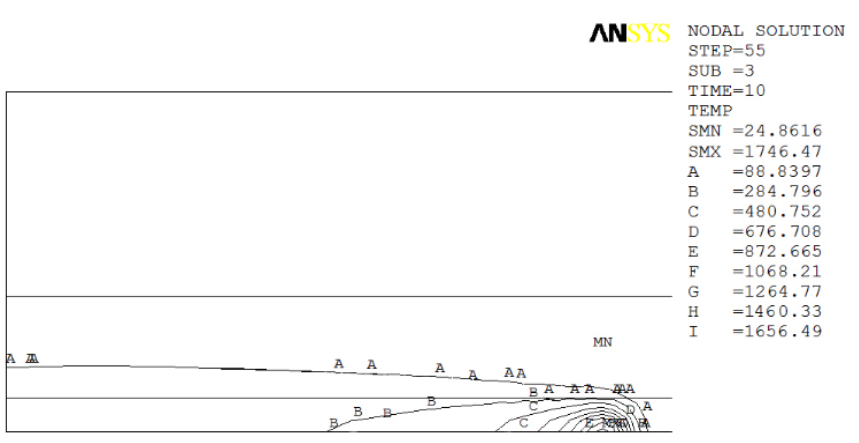

e

Fig. 4 Distribution diagram of transient temperature field: a $-t=2 \mathrm{~s} ; \mathrm{b}-t=4 \mathrm{~s} ; \mathrm{c}-t=6 \mathrm{~s} ; \mathrm{d}-t=8 \mathrm{~s} ; \mathrm{e}-t=10 \mathrm{~s}$ 
Table

Thermo-physical properties of $16 \mathrm{Mn}$

\begin{tabular}{|c|c|c|c|}
\hline $\begin{array}{c}\text { Temperature } \\
T,{ }^{\circ} \mathrm{C}\end{array}$ & $\begin{array}{l}\text { Density } \\
\rho, \mathrm{kg} / \mathrm{m}^{3}\end{array}$ & $\begin{array}{c}\text { Coefficient of thermal } \\
\text { conductivity } \\
\lambda, \mathrm{W} / \mathrm{mK}\end{array}$ & $\begin{array}{l}\text { Specific-heat capacity at constant pressure } \\
\qquad C, \mathrm{~J} /(\mathrm{kgK})\end{array}$ \\
\hline 20 & \multirow{6}{*}{7850} & 53.17 & 461 \\
\hline 100 & & 51.08 & 482 \\
\hline 200 & & 47.73 & 523 \\
\hline 300 & & 43.96 & 557 \\
\hline 400 & & 39.57 & 607 \\
\hline 500 & & 36.01 & 678 \\
\hline
\end{tabular}

\subsection{Thermal cycle curve of CMT welding}

Fig. 5 shows the thermal cycle curve at points with different distance in width direction from the center of steel plate. With the change of distance of each point from the center of steel plate, the thermal cycle curve varies significantly, with a greater difference at the highest temperature and trend of curve change. At $y=0.8 \mathrm{~cm}$, the temperature both decrease and increases very rapidly; and at $\mathrm{y} \geqq 5 \mathrm{~cm}$, the temperature curve changes more slightly, and the highest temperature also drops greatly.

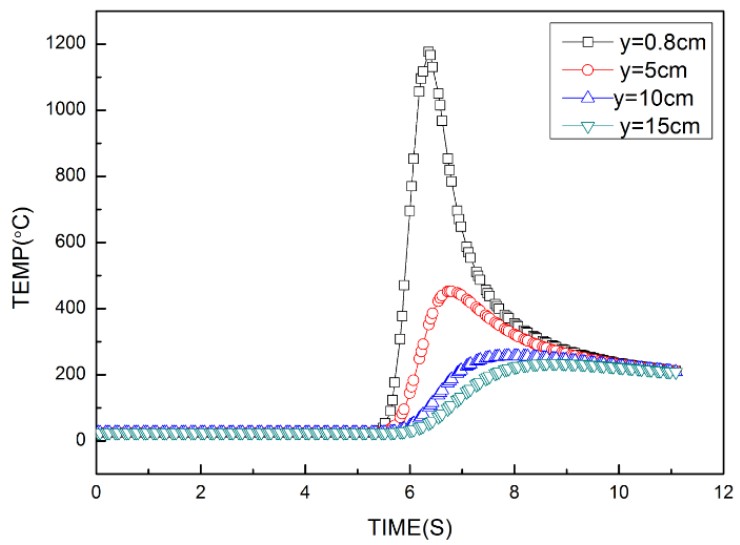

Fig. 5 Thermal cycle curve points with different distance in width direction from the center of steel plate

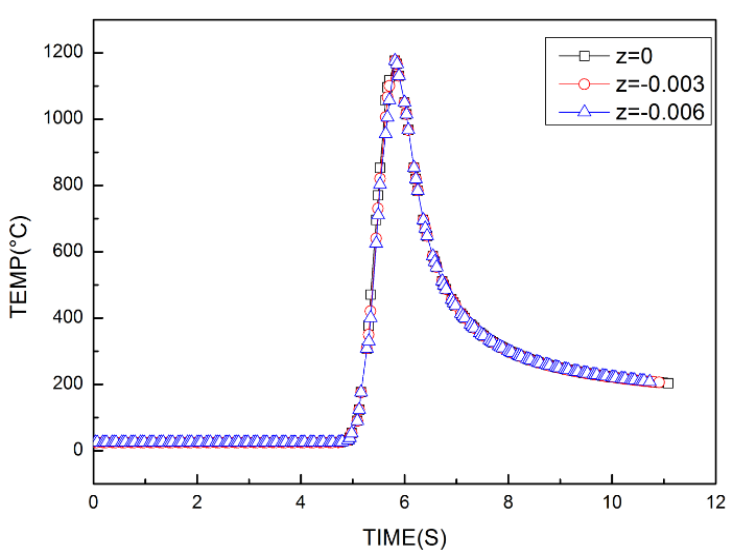

Fig. 6 Thermal cycle curve at points with different distance in height direction from the center of steel plate

Fig. 6 shows the thermal cycle curve at points with different distance in height direction from the center of steel plate. Despite the different distance from the center of steel plate, the thermal cycle curve varies very slightly. As is seen from Fig. 6, the plate temperature increases at very high velocity (i.e. from the room temperature to the highest temperature within 1s)to the highest temperature which subjects to only trivia changes as the distance diverse, and then the metal is cooled very rapidly (i.e. from the highest temperature to $300^{\circ} \mathrm{C}$ within $1 \mathrm{~s}$ ).

\section{Verification of numerical simulation experiment for the temperature field}

The welding experiment is made through the TPS5000 welding system (from Austrian Fronius Co.). This DSP-based welding system integrates the welding expert system for combination of various welding processes, including: MIG welding, pulsed MIG welding, CMT welding, as well as CMT-pulsed MIG combined welding. During the experiment, the temperature was measured through a K-type thermocouple (measurement range $0 \sim 1300^{\circ} \mathrm{C}$ ) connected to a multi-channel temperature logger for recording the measured result. Before the temperature measurement, a hole should be fabricated at the position 1 of the workpiece as specified in the following diagram (position 0: central point of the workpiece; position 1: edge of the welding seam). During the temperature measurement, one end of the $\mathrm{K}$ type thermocouple is embedded in the pre-fabricated hole. Fig. 7 shows the schematic diagram of temperature measuring system.

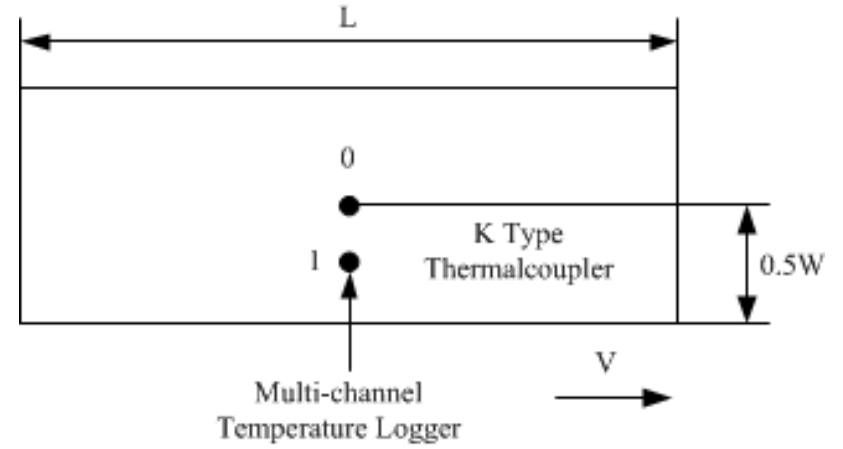

Fig. 7 Distribution of measuring points in the temperature field

Fig. 8 compares the thermal cycle curve calculated during the welding with the measured thermal cycle curve. During the welding, when the thermal source moves along the workpiece, the temperature at a certain point of workpiece first increases, reaches the highest level and then drops as the time goes on. The trend of measured thermal cycle curve is same as that of calculated thermal cycle curve, further demonstrating that the numerical simulation is reliable. 


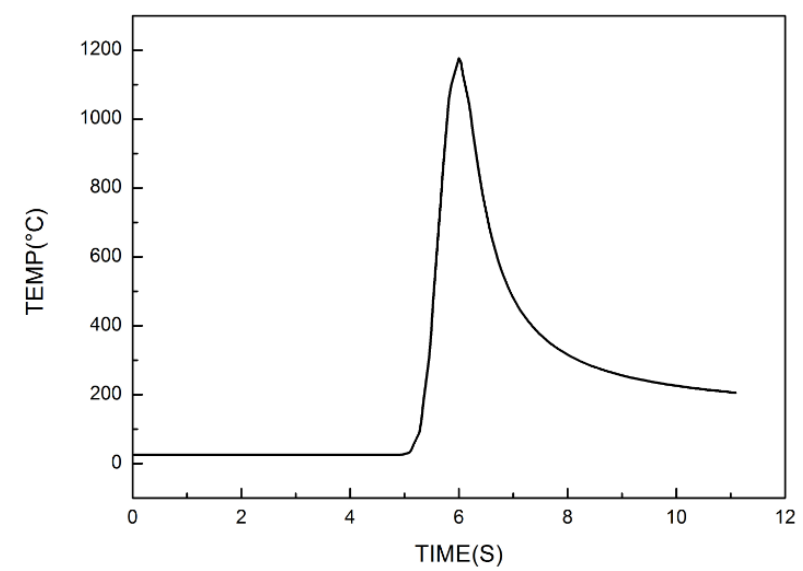

a

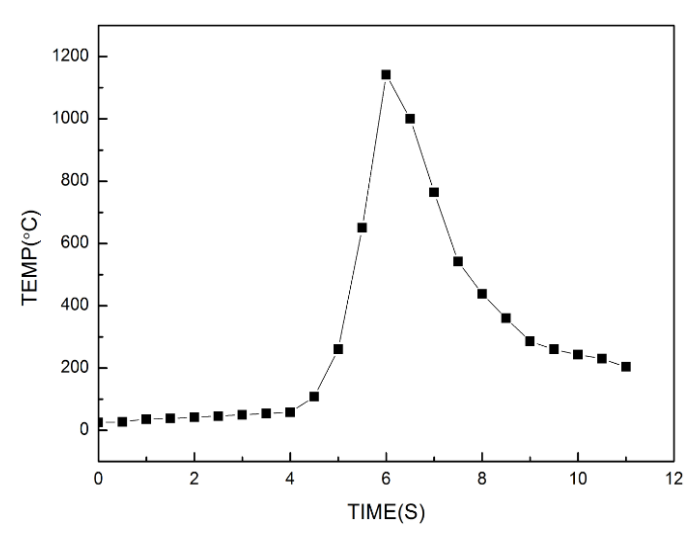

$\mathrm{b}$

Fig. 8 Calculated thermal cycle curve contrasting with measured curve: a - calculated thermal cycle curve (simulation); b - measured thermal cycle curve

\section{Conclusions}

1. Through the ANSYS software, a numerical simulation model is established for the temperature field of CMT welding pool to simulate the dynamic change of this temperature field under the action of a mobile thermal source.

2. The measured thermal cycle curve fits well with the calculated thermal cycle curve, demonstrating that the numerical simulation model for the temperature field of CMT welding pool established in this article is reliable.

3 . The numerical simulation method can accurately simulate the distribution conditions of temperature field on the workpiece during the CMT welding, so as to make a reliable prediction for analyzing the temperature field of CMT welding pool and thus offer a reference basis for simplifying the CMT welding experiment and choosing the parameters of CMT welding process.

\section{Acknowledgements}

This material is based upon work supported by the National Science Foundation of China (Grant no. 51205136), the Competitive Allocation Project Special Fund of Guangdong Province Chinese Academy of Sciences Comprehensive Strategic Cooperation (Grant no. 2013B091500082), the Science and Technology Planning Project of Guangdong Province, China (Grant No. 2013B010402002) and the Fundamental Research
Funds for the Central Universities (Key Program) (Grant no. 2015ZZ084)

\section{References}

1. Talalaev, R.; Veinthal, R.; Laansoo, A. 2012. Cold metal transfer (CMT) welding of thin sheet metal products, Estonian Journal of Engineering 18(3): 243-250. http://dx.doi.org/ 10.3176/eng.2012.3.09.

2. Pickin, C.G.; Williams, S.W.; Lunt, M. 2011. Characterisation of the cold metal transfer (CMT) process and its application for low dilution cladding, Journal of Materials Processing Technology 211(3): 496-502. http://dx.doi.org/ 10.1016/j.jmatprotec.2010.11.005.

3. Feng, J.C.; Zhang, H.T.; He, P. 2009. The CMT shortcircuiting metal transfer process and its use in thin aluminum sheets welding, Materials \& Design 30(5): 18501852. http://dx.doi.org/ 10.1016/j.matdes.2008.07.015.

4. Ola, O.T.; Doern, F.E. 2014. A study of cold metal transfer clads in nickel-base INCONEL 718 superalloy, Materials \& Design 57(5): 51-59. http://dx.doi.org/ 10.1016/j.matdes.2013.12.060.

5. Goldak, J.; Chakravarti, A.; Bibby, M. 1984. A new finite element model for welding heat sources, Metallurgical Transactions B 15(2): 299-305. http://dx.doi.org/ 10.1007/bf02667333.

6. Nart, E.; Celikl, Y. 2013. A practical approach for simulating submerged arc welding process using FE method, Journal of Constructional Steel Research 84(5): 62-71. http://dx.doi.org/10.1016/j.jcsr.2013.02.005.

7. Xin, W.T. 2011. ANSYS 13.0 Thermodynamics of finite element analysis from the entry to the master, Beijing: China Machine Press (in Chinese).

8. Li, P.L.; Lu, H. 2011. Sensitivity analysis and prediction of double ellipsoid heat source parameters, Transactions of the China Welding Institution 32(11): 89-91, 95.

9. Wu, C.S. 2007. Welding thermal processes and weld pool behaviors, Beijing: China Machine Press (in Chinese).

10. Pardo, E.; Weckman, D.C. 1989. Prediction of weld pool and reinforcement dimensions of GAM welds using a finite-element model. Metallurgical Transaction B 20(6): 937-947.

http://dx.doi.org/ 10.1007/bf02670199. 
Kai-Yuan Wu; Zu-Wei He; Zhong-Li Dong; Yan-Lin Lan

NUMERICAL SIMULATION OF THE TEMPERATUR FIELD OF COLD METAL TRANSFER WELDING POOL

$\mathrm{Su} \mathrm{m} \mathrm{m}$ ar $\mathrm{y}$

A thermal source model of cold metal transfer (CMT) welding is established, and the dynamic behavior of temperature field of CMT welding pool is simulated, and the corresponding distribution rule for temperature field is obtained. By combining the experimental measurement with ANSYS finite element numerical simulation, the thermal cycle curve of $16 \mathrm{Mn}$ steel surfacing welding is compared.
The result of finite element calculation well consists with that of experimental measurement, demonstrating that this finite element numerical simulation model is reliable. The analysis of temperature field of CMT welding pool is reliably predicted, so as to offer a reference basis for simplifying the CMT welding experiment and choosing the parameters of CMT welding process.

Keywords: cold metal transfer, welding pool, temperature field, numerical simulation.

Received October 30, 2015 Accepted July 04, 2016 